Artículo Especial

\title{
La realidad del embrión humano pre-implantatorio. Una reflexión acerca del fallo de la Corte Internacional de Derechos Humanos del 2012
}

\author{
Mauricio Besio R. ${ }^{1}$ \\ 1 División de Obstetricia y Ginecología, Escuela de Medicina, Pontificia Universidad Católica de Chile.
}

\section{RESUMEN}

El fallo de la Corte Interamericana de Derechos Humanos del 28 de Noviembre del 2012, ha causado preocupación. Es evidente que toda sentencia relacionada con los derechos más elementales de la persona humana tiene relevancia para los directamente involucrados como también para toda la sociedad. Todo tribunal de justicia tiene la misión de ponderar los bienes jurídicos en juego y fallar respetando la jerarquía de esos bienes. Para ello debe considerar la verdad de los hechos acaecidos, y también la verdad de los hechos naturales relevantes para el caso que juzga. Sin embargo, no le corresponde de ninguna manera determinar el valor de verdad de una realidad. Pretender establecer que el embrión humano pre-implantatorio no es una persona no le corresponde a ningún tribunal de justicia. Ni siquiera la ciencia experimental por sí sola puede llegar a determinarlo. Para ello se requiere además del aporte de la biología, el buen uso de la razón, que primero capta lo esencial de esa realidad para luego en su función deliberativa discurrir lógicamente para concluir y concebir un conocimiento.

\section{PALABRAS CLAVE: Persona, embrión, concepción, derecho a la vida}

\section{SUMMARY}

The sentence of the Inter-American Court of Human Rights of November 28, 2012, has caused concern. It is clear that any judgment related to the most basic rights of the human person has relevance for those directly involved as well as for all society. Every court has the task of weighing all the juridical goods in game and decide taking care of their hierarchy. For it, he must consider the truth of the happened events, and also the truth of the natural facts that are relevant for the case in question. Nevertheless, it does not correspond to him by any means to determine the indeed value of a reality. To try to establish that the pre implantatory human embryo is not a person does not correspond to any court of justice. Not even the experimental science herself can go so far as to determine it. For it, it is needed in addition to the contribution of the biology, the proper use of reason, that first captures the essence of that reality and then in its deliberative function, flows logically to conclude and conceive a knowledge.

KEY WORDS: Human person, embryo, conception, right to life 


\section{INTRODUCCIÓN}

La Corte Interamericana de Derechos Humanos dictaminó en su fallo del 28 de Noviembre del 2012 que "el embrión no puede ser entendido como persona para efectos del artículo 4.1 de la Convención Americana", que "la concepción" en el sentido del artículo 4.1 "tiene lugar desde el momento en que el embrión se implanta en el útero"(1) y que la sentencia de la Corte Suprema de Justicia de Costa Rica del año 2000, que prohibió la fecundación in vitro (FIV), "partió de una protección absoluta del embrión que, al no ponderar ni tener en cuenta los otros derechos en conflicto, implicó una arbitraria y excesiva intervención en la vida privada y familiar que hizo desproporcionada la interferencia"(2). Respecto a este fallo Zegers, Dickens y Dughman aseguran que las conclusiones del fallo "se traducen en que de acuerdo con la Convención los embriones in vitro no son "personas," y no tienen derecho a la vida" (3).

Sin tener competencia para pronunciarme sobre el alcance jurídico de ese fallo en los diferentes sistemas judiciales de los países sobre los cuales la corte tiene jurisdicción, ni tampoco sobre las interpretaciones y alcances de él en los casos particulares, cabe eso sí hacer una reflexión sobre los alcances y valor de verdad sobre el fallo y sobre las conclusiones que se extraen de él.

Es importante discernir para esos efectos, lo que le corresponde al Derecho, a las cortes de justicia y lo que le corresponde a las disciplinas que buscan conocer la realidad de las cosas y de los fenómenos vitales. En efecto, llama inmediatamente la atención los términos empleados en el fallo y los empleados por Zegers, Dickens y Dughman. Se podría llegar a pensar, leyendo esos términos, que realmente los embriones in vitro no son "personas," y no tienen derecho a la vida, zanjando definitivamente lo que científicos, filósofos y teólogos han intentado dilucidar desde tiempos inmemorables. La gravedad y riesgos de esta pretensión serían abismantes. Más grave aún, abriría las puertas a pensar que todo conocimiento es determinado por las cortes de justicia. Como eso no parece razonable, parece indispensable reflexionar más serenamente sobre el tema, para así poder determinar los distintos ámbitos de las instituciones y disciplinas y evitar graves daños a bienes que debemos procurar defender.

\section{EL ÁMBITO DEL DERECHO}

Al Derecho le corresponde establecer las relaciones entre los ciudadanos, personas naturales, jurídicas, naciones y países. Las cortes de justicia deben dirimir los conflictos entre todos ellos, buscando lo justo y protegiendo bienes universalmente aceptados. Evidentemente, es fácil darse cuenta que si bien todos podremos concordar con lo recién dicho, no es fácil para quienes les corresponde, determinar lo justo en cada situación particular. Existen bienes diversos que es necesario jerarquizar, circunstancias variadas y doctrinas jurídicas desde donde se fundan los cuerpos legales, también diversas. Recordemos solamente aquellas fundadas en el derecho natural, es decir en la naturaleza de las cosas y las fundadas en acuerdos y convenciones consensuadas (derecho positivo).

Debido a lo anterior, frecuentemente los fallos no dejan satisfechos a las partes involucradas. Recordemos como ejemplo las sentencias recientes de la corte internacional de la Haya, afectando los intereses de países americanos, entre ellos el nuestro. Además de las razones expuestas existe otra que explica que las decisiones judiciales sean discutibles; los fallos judiciales son esencialmente contingentes, es decir, versan sobre materias que pueden ser de infinitas maneras y que tienen varias opciones de resolución. Es por ello que los tribunales son frecuentemente colegiados, existiendo en ellos fallos de mayoría y de minoría y además instancias de apelación.

Las sentencias judiciales no determinan una verdad científica, no le corresponde establecerla y nadie pretende que lo hagan. La ciencia, en cambio intenta establecer la verdad acerca de realidades que existen de una manera determinada, es decir de realidades necesarias o que son de una sola manera. En cambio la verdad que busca establecer un tribunal es la verdad sobre hechos contingentes, es decir que pueden haber sido de muchas maneras, y esa verdad buscada es una adecuación de los hechos acaecidos con cuerpos legales o principios jurídicos de mayor jerarquía o con fallos anteriores en casos similares (jurisprudencia).

El fallo de la corte interamericana de derechos humanos es un fallo iniciado por una contingencia, lo sucedido pudo haber sido de esa manera o de otra. Las conclusiones son la verdad que la mayoría de los jueces integrantes encontraron al comparar lo ocurrido con situaciones similares, juzgadas en otros tribunales y/o al relacionar los hechos con cuerpos legales de mayor jerarquía. Si nos fijamos en las conclusiones, ellas no pretenden determinar una verdad científica, no pretenden haber llegado a conocer realmente lo que el embrión es antes de la implantación (más bien lo que no es). Lo que pretenden es comparar los bienes jurídicos en

\footnotetext{
${ }^{1}$ Corte Interamericana de Derechos Humanos Caso Artavia Murillo y otros ("fecundación in vitro") vs. Costa Rica Sentencia de 28 de noviembre de 2012 . Art.264. 2lbid. art. 316.

3Zegers F., Dickens B.M., y Dughman S,. Human Rights to In Vitro Fertilization. Int J Gynecol Obstet 2013;123: 86-89.
} 
cuestión -el derecho a tener una familia, acceder a terapias, el derecho a la vida-con la jurisprudencia y con normas de mayor jerarquía; concluyen así que el embrión no implantado no sería una persona. Tanto es así que en sus conclusiones se señala claramente que no sería persona "para efectos del artículo 4.1 de la Convención Americana".

Es obvio que para llegar a un fallo, unánime o de mayoría, la corte utiliza, además de la información jurídica sobre la jerarquía de las normas o la jurisprudencia existente, información aportada por peritos en los temas que tienen relevancia en el caso estudiado. Los jueces no son expertos en todos los temas. Es así que diversos especialistas concurren aportando la información que los jueces requieren para fallar. Los jueces no son expertos en materias particulares, pero esos expertos sólo lo son en sus materias. Evidentemente los jueces pueden solicitar o aceptar, además, opiniones de esos expertos sobre el tema en discusión, sin embargo deben ponderar adecuadamente la información experta sin confundirla con las meras opiniones, y tener suficientemente claro cuál es el campo de conocimiento de cada especialista.

En teoría sobre el conocimiento científico conseguido no debería haber discusión. Podría haberla sobre si realmente es un verdadero conocimiento científico, pero si es verdadero no hay discusión ya que ese conocimiento es nada más y nada menos que la realidad -que es de una determinada manera- conocida. Que sea verdadera implica además que abarca todas las dimensiones y complejidad de esa realidad. En el estado actual es muy difícil que exista un experto que sea capaz de abarcar toda esa complejidad, de allí el esfuerzo interdisciplinario. Es frecuente que expertos en determinadas materias emitan conclusiones basadas en el conocimiento experto de su campo, pero invadiendo el de otras disciplinas que estudian esa misma realidad. Eso no sería problema si fuera experto en ambos campos, o tuviera conciencia que sus conclusiones, ahora fuera de su área, son meras opiniones. Los jueces deben ser capaces de esta distinción para cautelar que la ayuda solicitada sea realmente la que necesitan para fallar en justicia.

Está claro que determinar si el embrión humano es o no es una persona, no es un tema susceptible de ser resuelto por un fallo judicial, por muy importante o por muy obligatorio que pretenda ser su cumplimiento.

\section{EL ÁMBITO DE LA CIENCIA EXPERIMENTAL}

Cuando hablamos de ciencia, nos referimos a una actividad que busca conocer como es una realidad, que no conocemos. Aspiran a ser ciencias la física, que estudia el comportamiento de los cuerpos y la biología, que estudia como son los seres vivos. En ese sentido aspira también a ser ciencia la filosofía que estudia la misma realidad, pero en sus causas más radicales. Si el biólogo estudia a los seres vivos, su estructura y conducta, la filosofía se pregunta por la vida y la existencia.

Como vemos, tanto la biología, la física y la filosofía estudian la realidad. Nadie podría negar la importancia que tienen todas esas disciplinas para lograr dar respuesta a nuestras interrogantes y a los dilemas que tenemos como sociedad. Desgraciadamente, en los últimos siglos, con demasiada frecuencia ha existido una separación entre las llamadas ciencias "duras" o experimentales como la física, química o biología, con otras como la filosofía, que no ocupa como metodología el análisis estructural o experimental con sus objetos de estudio, sino que privilegia la síntesis o captación de lo más esencial y radical. Con todas se puede enriquecer el estudio, salvo que alguno considerara que el ámbito de una de ellas es el único real y el único que explique y permita comprender lo existente. El riesgo de ello es considerable. Si algo es estudiado en solo una de sus dimensiones, la riqueza de su realidad se reduce a esa sola dimensión. El ser humano, por ejemplo, sería considerado sólo como una estructura física o sólo como una inmaterialidad, como si fuese un ángel. Eso no solo impide conocer su realidad, sino que también impide determinar cuál es el trato que merece recibir.

Otro aspecto que hay que tener presente es que al considerar como real sólo una dimensión, se dificulta encontrar las respuestas adecuadas a los problemas que se intentan solucionar. Es inevitable entonces que se tienda a "invadir" el terreno de otras disciplinas, sin tener la capacitación necesaria para hacerlo. En el caso que nos preocupa, la naturaleza del embrión humano pre-implantatorio y el fallo de la Corte Interamericana de Derechos Humanos, podríamos decir que los datos biológicos -los obtenidos por la biología y entregados por los peritos- nadie los podría contradecir. Encontraríamos un acuerdo prácticamente total si los confrontáramos con otros expertos de esa área. En otras palabras, el encuentro entre los gametos, el proceso de fertilización, el desarrollo embrionario, el transporte por las trompas de Falopio y la implantación, ocurren de una manera en que todos los entendidos estarían de acuerdo en sus aspectos más importantes, o por lo menos relevantes para el caso en discusión. Sin embargo, en el determinar cuándo empieza la vida de una persona, o si le debemos otorgar el estatuto de 
persona a un embrión no implantado, el asunto cambia.

El asunto cambia, ya que ahora no estamos en el terreno de la biología. Las respuestas a esas preguntas que, por cierto nos interesan tanto como para llegar a una corte de justicia internacional, requieren de otras aproximaciones y otras metodologías. Pero esas aproximaciones y metodologías son bastante más rigurosas que, por ejemplo, las consultas a un diccionario, por muy prestigioso que este sea. De hecho, los autores de los diccionarios no especializados no pretenden describir una realidad, sino que más bien determinar el significado corriente de los términos de un idioma. $Y$ a pesar de ello igualmente son cuidadosos en aportar todas sus acepciones, para que todo lo significado por el vocablo quede suficientemente determinado. Esto último tendrá relevancia en nuestra reflexión.

\section{DISCUSIÓN}

El tema del inicio de la vida humana ha apasionado a los pensadores desde el comienzo de la historia del hombre. Es fácil imaginar que el hombre primitivo, desde que fue capaz de extraer a partir de meras observaciones de lo que ocurría a su alrededor, un conocimiento conceptual y más universal, fue progresivamente entendiendo las causas que explicaban esos hechos observados. Esa comprensión aun no ha terminado y es perfectamente pensable, que nunca podamos entender totalmente con nuestras facultades naturales el origen y la explicación de esos fenómenos, que constituyen la realidad que nos rodea.

Lo único observable en relación con la generación de un nuevo ser vivo, en esos remotos tiempos, era que una hembra cualquiera en un momento dado paría un nuevo individuo, que con el tiempo adquiría una figura similar al resto de su especie. También se observaba y se experimentaba que individuos de distinto sexo se apareaban, que el macho depositaba en el cuerpo de la hembra cierta emanación corporal y que eran solo ellas las que posteriormente parían. Estas y muchas otras observaciones, que se repetían con regularidad, permitieron que la inteligencia de ese hombre primitivo utilizara esa suma de hechos particulares y pudiera concebir en su mente algo original y nuevo, que en la realidad no existía, ya que en ella existían solo esos hechos particulares. Lo nuevo y original era un concepto, un conocimiento, que daba cuenta y explicaba el por qué una hembra y no otras paría. El parto era causado por el apareamiento, a pesar de la distancia temporal entre ambos hechos.
Mucha agua ha corrido por los ríos desde esa primera aprehensión y conceptualización del misterio de la generación y perpetuación de los vivientes. Han sido necesarias numerosas observaciones, creación de instrumentos y experimentación a través de los años, para lograr extraer de lo observado suficientes datos para concebir nuevos conocimientos sobre las causas de esa generación, conocimientos no exentos de errores y posteriormente corregidos. Se puede recordar como ejemplo, las concepciones sobre un hombrecito completo (homúnculo) dentro de un espermatozoide, a partir del descubrimiento de ellos por Anton van Leeuwenhoek.

Es importante tener presente en toda la aventura del conocimiento humano, que existe una realidad que se despliega, independientemente de las ansias de la inteligencia humana de conocerla en la totalidad de sus detalles. Si no existiera el ser humano es posible imaginar que esa realidad seguiría desplegándose siguiendo sus propias reglas y causalidades. El ser humano pretende conocer esa realidad y también transformarla, pero para eso requiere producir en su mente un concepto de esas reglas y causalidades, ya que conocer realmente un fenómeno es conocer sus reglas y causas y no sólo tomar noticia de hechos.

Existe por lo tanto una realidad con sus reglas y causas, y la posibilidad de entenderla. Para hacerlo debe concebirse un conocimiento, que no es inmediato, primero es confuso y parcial. Mediante el esfuerzo de la ciencia y de la filosofía se va haciendo cada vez más nítido y completo, siempre que se eviten errores que lo impidan. Errores que se cometieron, desde la perspectiva de la ciencia -entendida como todas las disciplinas que estudian la realidad- en el fallo de mayoría de la Corte Interamericana de Derechos Humanos.

No me corresponde discutir la validez jurídica del fallo, pero sí el valor de verdad que se puede pretender establecer con él. Las consecuencias en la profesión médica y en la sociedad pueden ser muy relevantes, ya que establecer como verdad que el embrión humano antes de su implantación no es persona, lo expone a ser considerado una cosa, un bien transable y disponible.

El error se inicia no en la consideración de los derechos y los bienes que habrían sido afectados por el fallo de la Corte Suprema de Justicia de Costa Rica, si no que en la consideración parcial de la realidad del embrión, lo que lo situó en un estatuto con un valor muy inferior a esos derechos y bienes. En efecto, el embrión humano -si bien es cierto fue considerado adecuadamente desde el ámbito de 
la ciencia experimental- fue apreciado de manera muy inapropiada desde su consideración esencial y radical. De hecho, la información "biológica" aportada por los peritos es la aceptada como conocimiento establecido por todos los expertos de esa área. Sin embargo, al ser insuficiente para establecer el verdadero estatuto del embrión humano, se recurrió a argumentaciones, ahora desde el ámbito de la filosofía, evidentemente pobres, erradas y contradictorias.

Aunque parezca reiterativo, no se puede determinar si el embrión humano es o no una persona solamente desde la biología. La razón es muy simple, el concepto "persona" no es un concepto biológico, sino filosófico. No hay nada biológico en ese concepto. La biología puede aportar elementos de juicio relevantes para lograr determinar si un embrión pertenece o no a la especie humana y si es persona, pero eso es insuficiente si no se realiza un razonamiento adecuado y riguroso; eso es responsabilidad de la filosofía. Esto no ocurrió en las conclusiones del fallo. Es necesario explicar la razón de ello.

El principal argumento "filosófico" para concluir que el embrión humano pre- implantatorio no es una persona fue el siguiente: Según la Corte, lo que condicionaría el inicio de una nueva persona sería la implantación. Existirían hechos biológicos que permitirían deducir esto y además existiría otro argumento contundente: el diccionario de la Real Academia de la Lengua Española señala "concebir" como "quedar preñada la hembra". Luego, y así concluye el fallo, la concepción o aparición en la existencia de un ser humano único y original (persona) ocurre con la implantación de "algo" en el útero materno. Además, otra conclusión derivada del diccionario: la "concepción o gestación sería un evento de la mujer, no del embrión" (4).

Ahora bien, el hecho biológico desde donde se deducen esas conclusiones, es que antes de la implantación no se detecta la presencia de gonadotrofina coriónica que se "detecta 7 días después de la fecundación, con el embrión ya implantado" (5) y, como concepción y gestación serían sinónimos, la concepción de un nuevo individuo se produce a partir de la implantación de "algo" en el endometrio.

La argumentación aparece como débil y falaciosa. De partida, se acoge la definición de concebir como "quedar preñada la hembra", pero se omiten las otras acepciones: "comenzara sentir alguna pasión o afecto" y "formar idea, hacer concepto de algo". Es obvio que concebir se aplica a la aparición de algo nuevo, que antes no tenía existencia. Así como el conocimiento, el concepto de algo aparece originalmente en la mente, y el afecto en lo que llamamos corazón, así la concepción siempre se ha entendido como la aparición en la existencia de un individuo nuevo y es evidente que lo nuevo en la generación de los vivientes surge en la fecundación. Tanto es así, que muchos que se dedican a realizar técnicas de fertilización asistida, nos hablan de "conceptus" para referirse a lo surgido en la fertilización. Así también lo han entendido los mismos que ahora señalan que la concepción es la implantación o gestación: "Estamos convencidos de que una nueva vida comienza con la fecundación." (6).

Que un nuevo individuo comienza ya en la fecundación no se discute siquiera en los libros de embriología, cito al Langman, uno de los textos más conocido por los médicos: "De una simple célula a un bebé en 9 meses; un proceso de desarrollo que representa una extraordinaria integración de fenómenos cada vez más complejos" (7). Un nuevo individuo aparece a la existencia, se concibe, en la fecundación. Desde ese momento existe un organismo con un proceso continuo de desarrollo. Pero suponiendo que no fuese así, que apareciera a la existencia, se concibiera, en la implantación o gestación, parece necesaria una explicación, sin la cual se ofendería la inteligencia de cualquier lector. ¿Qué es ese "algo" que se implanta y hace surgir un nuevo organismo? Si fuese sólo "un conjunto de células o tejidos" (8), no habría forma de explicar como por el sólo hecho de implantarse en el endometrio, surge un individuo nuevo sin ser ese "algo" ni siquiera gametos. En el endometrio, por otro lado, no hay nada que al unirse a otra cosa permita la generación de un organismo. No habría progenitores y tendríamos que volver a aceptar la generación espontánea de los vivientes, descartada hace bastante tiempo por la ciencia. En otras palabras, para que surgiera un nuevo ser humano al transferir el técnico ese "conjunto de tejidos y células", implantarse en el endometrio y provocar una gestación en la mujer sería necesario un acto de magia o un milagro.

Veamos otra de las conclusiones del fallo, expresada a modo de verdad científica: "concepción o gestación sería un evento de la mujer, no del embrión”. Al analizarla podemos aceptar que la gestación, preñez o embarazo es efectivamente un evento de la mujer, pero no la concepción. Ninguna mujer está embarazada por el hecho de tener de embriones crioconservados, pero tampoco una mujer está embarazada sin la presencia de un embrión o feto implantado en su cuerpo. Intentar asimilar la concepción con la gestación genera bastantes dificultades con la realidad y con un pensamiento

\footnotetext{
${ }^{4}$ Artavia Murillo y otros. ("Fecundación In Vitro") vs. Costa Rica, Corte Inte-

7Langman. EMBRIOLOGÍA MÉDICA. Edición española de la obra original ramericana de Derechos Humanos, Sentencia de 28 de noviembre de 2012. Art.181 
lógico. La gestación sería la potencia generadora, y habría que explicar entonces cómo aparece una gestación sin la acción de un embrión. Además, si la gestación fuese la aparición a la existencia de un nuevo individuo -y sabemos que la gestación o embarazo no es un evento sino un proceso iniciado en la implantación y terminado con el parto- tendríamos que aceptar que la aparición a la existencia de un nuevo individuo (concepción), en realidad no ocurre en la implantación sino que está ocurriendo en los nueve meses que dura un embarazo. Un feto de 22 semanas se estaría concibiendo y otro de 38 semanas también. Además, si la implantación es el acontecimiento que causa, otorga o explica la vida de un nuevo individuo, el parto, al des-implantarse el feto, tendría que ser el evento que causa la muerte de ese individuo, ya que la mujer deja de estar embarazada. Ni lo uno ni lo otro ocurre, lo que se implanta es ya un nuevo individuo que requiere implantarse para el despliegue de sus potencialidades, hasta alcanzar un nivel de desarrollo suficiente para desprenderse y continuar su vida. Ninguna vida nueva puede surgir de un útero, pero sí puede un organismo implantarse en él. Ningún embarazo puede desarrollarse normalmente sin la presencia de ese organismo implantado.

Me parece que debemos dejar de "torcer" la realidad. Sin duda que es un problema aceptar que la vida de un nuevo individuo se inicia en la fecundación para los que intentan ayudar a las pacientes a través de las técnicas de reproducción asistida. A nadie le motiva aparecer manipulando y arriesgando la vida de las personas, ya que a todos los profesionales de la salud nos motiva y compete ayudar a nuestros pacientes a superar una enfermedad. Sin embargo, debemos intentar argumentar de manera adecuada. La tesis explicitada en el fallo de la Corte Interamericana de Derechos Humanos es bastante rebuscada, en oposición a la protección de la vida humana otorgada por la Convención Americana de Derechos Humanos (9). Frente a la claridad del artículo solo restaba la deconstrucción del término concepción, a través de una de las acepciones de un diccionario no especializado, forzando su uso habitual.

\section{CONCLUSIÓN}

La Corte Interamericana de Derechos Humanos ha emitido un fallo relacionado con un tema de altísima relevancia para las parejas infértiles, cuya única posibilidad de lograr tener un hijo en brazos, es mediante la utilización de técnicas de fertilización asistida. Es necesario reconocer, sin ser un experto en temas jurídicos, que el fallo debe representar una satisfacción para los que realizan estos procedimientos de una manera que implica la manipulación, crioconservación y riesgo vital de los embriones conseguidos. La sentencia implicará seguramente una mayor facilidad para la utilización de estos procedimientos en los países que de alguna manera pueden o deben aplicarla. Muchas parejas o mujeres podrán acceder a ellas y lograr satisfacer el legítimo anhelo de ser madres y padres.

Fijémonos, sin embargo, en las consecuencias de este fallo, si el embrión humano antes de su implantación fuese realmente un ser humano. La manera como se realizan las técnicas de reproducción asistida -salvo algunos intentos en algunos centros de hacerlas en ciclo espontaneo- se hacen por razones fundamentalmente de costo-efectividad, estimulando la ovulación y generando un mayor número de embriones que los que se transferirán. Todo esto implica riesgos de mortalidad para ellos, sin considerar la indignidad de mantener a muchos de ellos congelados con incierto futuro.

Es entonces de suma gravedad desprender de un fallo judicial un juicio de veracidad científica. Para actuar correctamente es indispensable tener el mayor conocimiento posible de la realidad. La información parcial, sesgada o reductiva impide tomar las decisiones adecuadas, que en el caso que nos ocupa tiene consecuencias graves. No es indiferente el estatuto del embrión humano. Se debe exigir, para despojarle $\mathrm{u}$ otorgarle su dignidad humana, además de la información entregada por la ciencia, una adecuada fundamentación y argumentación. Eso no ocurrió en el fallo de la Corte Interamericana de Derechos Humanos, aunque tenga alguna validez jurídica.

Es ciertamente posible, desde las observaciones entregadas por la ciencia experimental, que como vimos todos compartimos, establecer hipótesis diversas sobre lo más radical y esencial de las realidades. Todas esas hipótesis en principio son válidas, ya que crear un concepto o conocimiento sobre algo no es fácil. Se requiere de un adecuado método científico para que aporte la mejor información sobre los aspectos cuantificables de esa realidad, pero además se exige una inteligencia aguda y un adecuado uso de nuestro razonamiento. Primero la inteligencia debe extraer de los objetos que caen a su escrutinio la mayor inteligibilidad y, en su dimensión deliberativa, debe razonar adecuadamente para que las conclusiones sean válidas. Esa primera acción de nuestra inteligencia es casi intuitiva, la poseemos todos, no se necesitan arduos estudios. Con ella una mujer, a quien su médico le 
informa que sus ovocitos fueron fecundados, sabe y se alegra por ello, ya que están allí hijos suyos. La segunda debe partir de principios autoevidentes y avanzar lógicamente, para que lo concluido tenga el suficiente valor para ser expuesto a una dis- cusión. Esto es lo que justamente, a mi entender, no ocurrió con la pretensión de otorgar validez a la conclusión de que los embriones humanos antes de su implantación no son personas. 